\title{
ANALISIS FINANSIAL PENGOLAHAN MINYAK JAHE DI ACEH BESAR (STUDI KASUS PADA PT. RAZ INTAN)
}

(Financial Analysis Ginger Oil Processing in Aceh Besar ( The Case Study on PT. Raz Intan)

\author{
Adelia Kusfianda ${ }^{1}$, Edy Marsudi ${ }^{1}$, T. Makmur ${ }^{1 *}$ \\ ${ }^{1}$ Program Studi Agribisnis, Fakultas Pertanian, Universitas Syiah Kuala
}

\begin{abstract}
Abstrak - Minyak jahe memiliki banyak fungsi, diantaranya digunakan dalam industri kosmetik, makanan, aromateraphy, dan farmasi. Tujuan penelitian ini yaitu untuk mengetahui kelayakan usaha pengolahan minyak jahe pada PT. Raz Intan secara finansial. Penelitian ini dilakukan di PT. Raz Intan Desa Jurong Peujera Kecamatan Ingin Jaya Kabupaten Aceh Besar dengan menggunakan metode studi kasus. Data kelayakan usaha dianalisis menggunakan kriteria kelayakan yaitu NPV, Net B/C, IRR, BEP, dan analisis sensitivitas. Hasil analisis kelayakan usaha minyak jahe pada PT. Raz Intan menunjukkan usaha tersebut layak dijalankan, dimana nilai NPV sebesar Rp 446.242.245, Net B/C sebesar 2,64, IRR sebesar 49,50\%, dan BEP sebesar 5,358 atau lamanya waktu yang dibutuhkan untuk terjadinya BEP yaitu 5 tahun 4 bulan 8 hari. Dari analisis sensitivitas dengan hasil perhitungan kriteria biaya produksi (cost) naik 10\% dan penerimaan (benefit) tetap diperoleh NPV sebesar Rp 83.061.190, Net B/C sebesar 1,27, IRR sebesar 23,46\% dan BEP diperoleh pada tahun ke 6 , bulan ke 10, hari ke 4. Untuk biaya produksi (cost) tetap dan penerimaan (benefit) turun 10\% diperoleh NPV sebesar Rp 38.436.965, Net B/C sebesar 1,14, IRR sebesar 20,38\% dan BEP diperoleh pada tahun ke 6, bulan ke 10, hari ke 16.
\end{abstract}

Kata Kunci : Jahe, Minyak Jahe, Kelayakan Usaha

\begin{abstract}
Ginger oil has many functions, such as is used in the cosmetics industry, food, aromateraphy, and pharmaceuticals. The purpose of this study is to determine the feasibility of ginger oil processing at the PT. Raz Intan financially. This research was conducted at PT. Raz Desa Intan Jurong Peujera Ingin Jaya subdistrict, Aceh Besar District by using the case study method. Data were analyzed using the feasibility of the eligibility criteria, namely NPV, Net B / C, IRR, BEP, and sensitivity analysis. The results of the analysis of the feasibility of ginger oil at PT. Raz diamonds indicate the business is eligible to run, which is the NPV Rp 446242 245, Net B / C 2.64, IRR 49.50\%, and BEP amounted to 5,358 or length of time required for the BEP is 5 years 4 month 8 days. From a sensitivity analysis with the calculated cost of production criteria (cost) increased $10 \%$ and the reception (benefit) remain NPV Rp $83,061,190$, Net B / C of 1.27, IRR of 23.46\% and BEP obtained in year 6 months to 10 days to 4 . for the cost of production (cost) fixed and reception (benefit) fell by $10 \%$ NPV Rp $38,436,965$, Net B / C of 1.14, IRR of $20.38 \%$ and BEP obtained in the year to 6 months to 10 days to 16.
\end{abstract}

Keywords: Ginger, Ginger Oil, Feasibility

\section{PENDAHULUAN}

Jahe (Zingiber Officinale) merupakan salah satu tanaman obat komersial yang sudah banyak dikenal masyarakat dan berupa tumbuhan rumpun berbatang lunak yang berasal dari Asia Pasifik yang tersebar dari India ke Cina. Indonesia sendiri merupakan salah satu dari lima besar Negara pengekspor jahe di dunia. Ekspor Indonesia akan komoditas jahe rata-rata 
meningkat 32,75\% per tahun. Data tahun 2002 menunjukkan volume ekspor jahe mencapai 43.193 ton (BPS, 2002).

Jahe merupakan salah satu tanaman yang memiliki banyak sekali manfaat dan fungsi dalam kehidupan masyarakat Indonesia. Oleh karena itu, komoditas jahe layak dijadikan sebagai salah satu komoditas unggulan dalam usaha pengembangan agribisnis dan agroindustri yang berwawasan pedesaan (Rukmana, 2000). Provinsi Aceh sebagai salah satu sentra produksi jahe sebenarnya mempunyai peluang yang cukup besar dalam pengembangan jahe. Walaupun demikian sampai saat ini petani belum mendapatkan nilai tambah yang maksimal dengan usahataninya. Kabupaten Aceh Besar merupakan salah satu daerah industri pertanian terbesar. Untuk lebih jelasnya mengenai Jumlah Produksi jahe, luas tanam, luas panen, dan produktivitas jahe di Kabupaten Aceh Besar pada Tabel 1.

Tabel 1. Luas Tanam, Luas Panen, Produksi, dan Produktivitas Jahe di Kabupaten Aceh Besar Tahun 2015

\begin{tabular}{|r|l|r|r|r|r|}
\hline No & \multicolumn{1}{|c|}{ Kecamatan } & $\begin{array}{c}\text { Luas Tanam } \\
\left(\mathrm{M}^{2}\right)\end{array}$ & \multicolumn{1}{|c|}{$\begin{array}{c}\text { Luas Panen } \\
\left(\mathrm{M}^{2}\right)\end{array}$} & $\begin{array}{c}\text { Produksi } \\
(\mathrm{Kg})\end{array}$ & $\begin{array}{c}\text { Produktivitas } \\
\left(\mathrm{Kg} / \mathrm{M}^{2}\right)\end{array}$ \\
\hline 1 & Lhoong & 20.200 & 1.080 & 450 & 0,42 \\
\hline 2 & Lhoknga & 11.000 & 56.000 & 240.000 & - \\
\hline 3 & Leupung & 20 & - & - & 2,8 \\
\hline 4 & Indrapuri & 20.000 & 7.000 & 196.000 & 5,33 \\
\hline 5 & Kuta Cot Glie & 10.296 & 420 & 2.239 & 3 \\
\hline 6 & Seulimeum & 80.000 & 50.000 & 150.000 & - \\
\hline 7 & Kota Jantho & 50.636 & 25.500 & 66.800 & - \\
\hline 8 & Leumbah Seulawah & 10.000 & - & - & - \\
\hline 9 & Mesjid Raya & 30.000 & - & - & 2,52 \\
\hline 10 & Darussalam & 22.595 & 20.000 & 100.000 & - \\
\hline 11 & Kuta Baro & 10.000 & 20.000 & 50.400 & 2,06 \\
\hline 12 & Montasik & 20.000 & - & - & 2,83 \\
\hline 13 & Kuta Malaka & 100 & 83 & 171 & 32,07 \\
\hline 14 & Peukan Bada & 20.000 & 20.000 & 36.530 & \\
\hline 15 & Pulo Aceh & 80.000 & 240.000 & 528.800 & \\
\hline & Jumlah & 38.4347 & 503.083 & 1.371 .390 & \\
\hline
\end{tabular}

Sumber: Dinas Pertanian dan Tanaman Pangan Kabupaten Aceh Besar, 2015

Berdasarkan tabel 1 dapat dilihat bahwa lahan yang paling luas adalah daerah Seulimeum dan Pulo Aceh, sedangkan luas lahan yang paling kecil berada di daerah Leupung. Sedangkan pada tingkat luas panen terbesar terdapat pada daerah Pulo Aceh dan luas panen terkecil terdapat pada daerah Kuta malaka. Daerah yang produksi panen yang paling tinggi terdapat pada daerah Pulo Aceh dan produksi panen terkecil terdapat pada daerah Kuta Malaka. Hasil persentase produktivitas tertinggi ada pada daerah Kuta Cot Glie dan hasil produktivitas terendah ada pada daerah Lhoong.

Komoditas jahe masih menjanjikan peluang besar untuk dikembangkan terus melalui pengembangan sumber-sumber pertumbuhan seperti optimalisasi produktivitas lahan usaha, produktivitas tanaman, penekanan kehilangan hasil baik pra panen maupun pasca panen, peningkatan mutu dan diversifikasi produk serta perdagangan bahan jadi produk dalam negeri. Salah satu usaha pengolahan jahe adalah PT. Raz Intan ini merupakan salah satu usaha pengolahan minyak atsiri di Desa Jurong Peujera Kecamatan Ingin Jaya Kabupaten Aceh 
Besar. Salah satu produk olahan jahe yang sangat bermanfaat adalah minyak atsiri jahe. Minyak jahe diketahui memiliki berbagai fungsi, diantaranya digunakan dalam industri kosmetik, makanan, aromaterapi, dan farmasi.

Minyak atsiri yang disuling dari jahe berwarna kuning bening sampai kuning tua bila bahan yang digunakan cukup kering. Usaha penyulingan minyak atsiri jahe memiliki masa depan yang cukup cerah.jahe tidak hanya berprospek di dalam negeri saja tetapi juga memiliki peluang besar untuk diserap oleh pasar internasional. Pasar internasional sekarang ini kembali melirik kekayaan alam dengan memanfaatkan potensi yang ada untuk dunia kesehatan dan kecantikan. PT. Raz Intan juga mengekspor minyak jahe ke salah satu perusahaan obat-obatan dan kecantikan di Malaysia yang orientasi pasarnya hingga benua Eropa. Dengan adanya produksi minyak jahe ini juga ada manfaat dari segi ekonomi yaitu jahe mempunyai nilai jual yang tinggi, petani jahe juga kebagian rezeki karena terserapnya jahe dari petani-petani lokal, terserapnya tenaga kerja, dan menghasilkan devisa untuk negara. Tujuan penelitian ini adalah untuk mengetahui kelayakan usaha pengolahan minyak jahe pada PT. Raz Intan Desa Jurong Peujera Kecamatan Ingin Jaya Kabupaten Aceh Besar secara finansial.

\section{METODOLOGI PENELITIAN}

Penelitian ini dilakukan pada usaha pengolahan minyak jahe PT. Raz Intan di Desa Jurong Peujera Kecamatan Ingin Jaya Kabupaten Aceh Besar. Objek penelitian adalah usaha Pengolahan minyak jahe studi kasus pada PT. Raz Intan. Ruang lingkup penelitian terbatas pada pendapatan yang diperoleh pada usaha pengolahan minyak jahe dan analisis finansial pada PT. Raz Intan di Desa Jurong Peujera Kecamatan Ingin Jaya Kabupaten Aceh Besar.

Metode yang digunakan dalam penelitian ini adalah metode studi kasus pada PT. Raz Intan. Penelitian studi kasus merupakan penelitian yang dilakukan terhadap objek penelitian atau sesuatu yang harus diteliti secara menyeluruh, utuh dan mendalam (Guba dan Lincoln, 1985). Data yang digunakan dalam penelitian ini berupa data primer dan data sekunder. Data primer yang diperoleh dengan cara wawancara dari pengusaha usaha pengolahan minyak jahe PT. Raz Intan. Sedangkan data sekunder, yang diperoleh dari studi kepustakaan, instansiinstansi terkait serta literature yang berhubungan dengan penelitian ini.

Metode analisis yang digunakan dalam penelitian ini adalah metode analisis deskriptif. Analisis ini digunakan untuk menganalisa data yang diperoleh dilapangan secara sistematis, aktual dan akurat mengenai fakta-fakta tertentu. Adapun metode analisis yang digunakan dalam penelitian ini melalui beberapa tahapan. Data yang telah diperoleh dari lapangan melalui pengamatan langsung dan wawancara dengan responden ataupun menggunakan daftar pertanyaan (quesioner), kemudian diolah dan ditabulasikan kedalam bentuk tebelaris yang sesuai dengan keperluan analisis. Maka pengujiannya dilakukan dengan prosedur kriteria investasi yaitu : Net Present Value (NPV), Net Benefit Cost ratio (Net B/C), Internal Rate of Return (IRR), dan Break Event Point (BEP) dan Analisis sensitivitas.

Untuk mengetahui kelayakan dari usaha pengolahan jahe dapat digunakan rumus sebagai berikut :

\section{a. Net Present Value (NPV)}

Net Present value (NPV) adalah nilai sekarang dari selisih antara benefit (manfaat) dengan cost (biaya) pada Discout Rate tertemntu. Dengan rumus sebagai berikut :

$$
N P V=\sum_{t=0}^{n} \frac{B_{t}-C_{t}}{(1+i)^{t}}
$$

(Kadariah, 1978) 


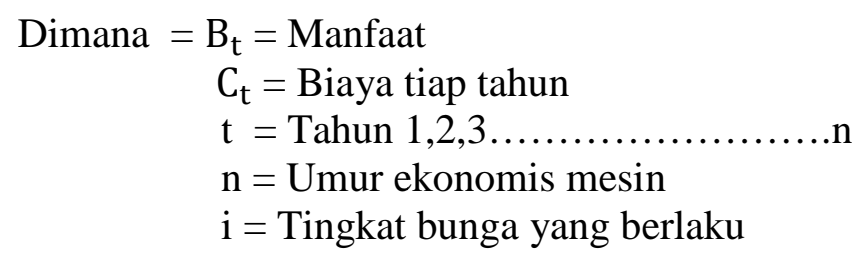

\section{b. Net Benefit Cost Rasio (Net B/C)}

Net B/C adalah perbandingan antara jumlah Net Present Value positif (NPV positif) dengan Net Present Value Negatif (NPV negatif). Dengan rumus sebagai berikut:

$$
\text { Net B/C Ratio } \frac{\sum_{t=0}^{t=n} N P V \text { Positif }}{\sum_{t=0}^{t=n} N \text { PV Negatif }}
$$

(Choliq A, 1994)

Jika Net B/C > 1, berarti usaha pengolahan minyak jahe layak untuk diusahakan Jika Net $\mathrm{B} / \mathrm{C}=1$, berarti usaha pengolahan minyak jahe tidak untung dan tidak rugi.

Jika Net $\mathrm{B} / \mathrm{C}<1$, berarti usaha pengolahan minyak jahe tersebut tidak layak untuk diusahakan.

Dimana :

$\sum$ NPV Positif $=$ jumlah NPV Positif yang telah di discount rate.

$\sum$ NPV Negatif = jumlah yang telah di discount rate.

\section{c. Internal Rate of Return (IRR)}

IRR merupakan nilai untuk mengetahui keuntungan dari usaha tiap-tiap tahun. IRR juga merupakan alat ukur kemampuan proyek dalam mengembalikan bunga pinjaman. Dengan rumus sebagai berikut :

$$
\operatorname{IRR}=i_{1}+\frac{N P V_{1}}{N P V_{1}-N P V_{2}}\left(i_{2}-i_{1}\right) \ldots \ldots \ldots \ldots \ldots \ldots \ldots \ldots \ldots \ldots \ldots \ldots \ldots \text { Ibrahim, 1998) }
$$

\section{Dimana :}

$\mathrm{i}_{1} \quad=$ Tingkat bunga pada percobaan pertama dimana diperoleh NPV positif

$\mathrm{i}_{2} \quad$ = Tingkat bunga pada percobaan kedua dimana diperoleh NPV negatif

$\mathrm{NPV}_{1}=$ Nilai NPV pada tingkat bunga $\mathrm{i}$ (positif menuju nol)

$\mathrm{NPV}_{2}=$ Nilai NPV pada tingkat bunga i (negative menuju nol)

Jika : IRR > Discount rate, maka usaha pengolahan jahe layak diusahakan.

IRR = Discount Rate, maka usaha pengolahan jahe berada pada titik impas dan layak untuk diusahakan.

IRR < Discount Rate, maka usaha pengolahan jahe tersebut tidak layak diusahakan. 


\section{d. Break Event Point (BEP)}

Break Event Point (BEP) adalah titik balik modal diman penerimaan sama dengan biaya. Dengan rumus sebagai berikut :

$$
\mathrm{BEP}=\mathrm{T}_{\mathrm{p}-1}+\frac{\sum_{t=1}^{n} T \bar{C}_{1}-\sum_{t=1}^{n} \bar{B}_{i c p-1}}{B_{p}}
$$

Dimana :

$\mathrm{T}_{\mathrm{P}-1}=$ Tahun sebelum terdapat BEP

$\mathrm{TC}_{\mathrm{i}} \quad$ = Jumlah total cost yang telah di discount

$\mathrm{B}_{\mathrm{icp}-1}=$ Jumlah benefit yang telah discount sebelum BEP

$\mathrm{B}_{\mathrm{p}} \quad=$ Jumlah benefit pada tahun terjadinya BEP

$\mathrm{n} \quad=$ Umur ekonomis usaha

\section{e. Analisis Sensitivitas}

Analisis sensitivitas atau uji kepekaan untuk melihat apakah uang akan terjadi dengan hasil nilai analisis proyek (manfaat dan biaya) karena dapat suatu kesalahan atau perubahan dalam dasar-dasar perhitungan (kenaikan harga faktor produksi atau penurunan harga jual produksi). Pada analisis kepekaan seriap kemungkinan harus diuji, yang berarti bahwa setiap perubahan harus dianalisis kembali. Hal ini dilakukan karena umumnya analisis suatu proyek didasarkan atas proyeksi-proyeksi yang banyak mengandung ketidak pastian. Perubahan dapat saja terjadi terhadap harga dan produksi, sehingga akan menyebabkan perubahan biaya dan penerimaan proyek.

Untuk menguji kepekaan usaha Pengolahan jahe di Kecamatan Ingin Jaya Kabupaten Aceh Besar diasumsikan :

- Biaya naik $10 \%$, benefit tetap. Biaya produksi naik sebesar $10 \%$ sedangkan penerimaan (gross benefit) tetap. Kenaikan harga ini diasumsikan sebagai akibat kelangkaan barangbarang produksi sehingga barang-barang tersebut meningkat.

- Biaya tetap benefit turun 10\%. Biaya produksi tetap sedangkan penerimaan (gross benefit) turun 10\%. Penurunan penerimaan ini diasumsikan sebagai akibat adanya kelebihan penawaran jahe di pasar, yang menyebabkan harga jahe mengalami penurunan sebesar $10 \%$.

\section{Karakteristik Pemilik Usaha}

Karakteristik pengusaha dalam penelitian ini meliputi umur, tingkat pendidikan, pengalaman kerja sebagai pengusaha pengolahan minyak jahe dan besarnya jumlah tanggungan keluarga. Karakteristik pengusaha ini merupakan salah satu unsur yang dapat mempengaruhi kemampuan seorang pengusaha dalam mengelola usahanya, peningkatan omset penjualan, mengefisieksikan penggunaan biaya yang dikeluarkan (biaya pemasaran) dan untuk meningkatkan keuntungan. 
Mengenai keadaan rata-rata karakteristik pemilik usaha pengolahan minyak jahe di daerah penelitian dapat dilihat pada Tabel 2 berikut.

Tabel 2. Rata-rata Karakteristik Pemilik Usaha Pengolahan Minyak Jahe PT. Raz Intan di Kabupaten Aceh Besar, Tahun 2016

\begin{tabular}{|c|l|c|c|}
\hline No & \multicolumn{1}{|c|}{ Uraian } & Satuan & Jumlah \\
\hline 1 & Umur & Tahun & 52 \\
\hline 2 & Pendidikan & Tahun & 17 \\
\hline 3 & Pengalaman Berusaha & Tahun & 3 \\
\hline 4 & Tanggungan & Jiwa & 4 \\
\hline
\end{tabular}

Sumber : Data diolah, Tahun 2016

Tabel 2 memperlihatkan keadaan rata-rata umur pengusaha pengolahan minyak jahe adalah 52 tahun. Batasan umur ini masih tergolong ke dalam umur yang produktif untuk bekerja. Pada usia produktif ini kesadaran seorang pengusaha untuk menambah pendapatan keluarga terus dipacu, karena adanya beban ekonomi untuk memenuhi kebutuhan hidup sehari-hari dan untuk membiayai pendidikan anak-anak mereka. Selain itu, daya pikir dan kekuatan fisik untuk bekerja masih sangat optimal, sehingga produktivitas kerja masih dapat ditingkatkan lagi.

Pendidikan rata-rata pengusaha pengolahan minyak jahe adalah tahun, ini artinya pengusaha rata-rata telah menamatkan pendidikan setingkat S2. Dengan tingkat pendidikan tersebut, pendidikan pengusaha pengolahan minyak jahe ini sudah cukup baik.

Pengalaman berusaha pengusaha rata-rata adalah 3 tahun. Keadaan ini menunjukkan bahwa pengusaha telah cukup berpengalaman dalam mengelola usaha dagangannya. Pengalaman yang cukup akan mempengaruhi kemampuan pengusaha dalam mengelola usahanya dengan lebih baik lagi.

Jumlah tanggungan keluarga pengusaha rata-rata 4 jiwa. Jumlah tanggungan akan mempengaruhi besarnya pengeluaran untuk konsumsi, sehingga persediaan modal atau keuntungan usaha menjadi berkurang. Oleh karena itu jumlah tanggungan yang ada harus dimanfaatkan sebagai sumber tenaga kerja dalam keluarga, sehingga dapat menghemat penggunaan biaya tenaga kerja dalam menjalankan usaha.

Suatu usaha yang baik menghendaki agar yang mengusahakannya berumur produktif, berpengalaman serta mempunyai tanggungan atau keluarga yang dapat membantu bekerja dalam perusahaannya. Dibandingkan dengan pengusaha yang telah lanjut usia, tidak berpengalaman dan mempunyai tanggungan keluarga yang tidak bekerja dalam kegiatan usahanya, sehingga dapat mengurangi keuntungan dari usaha yang dijalankan tersebut. Pendidikan, keahlian dan keterampilan yang dimiliki oleh seorang pengusaha sangat mempengaruhi kelancaran kegiatan usaha, terutama yang berhubungan dengan bidang usaha pengolahan minyak jahe.

Faktor umur akan berpengaruh terhadap kemampuan kerja pengusaha dalam mengelola usahanya. Pengusaha yang memiliki umur lebih muda, umumnya cenderung akan lebih bersemangat dalam berusaha dan sering melakukan perubahan-perubahan untuk kemajuan usahanya, jika dibandingkan dengan pengusaha yang lebih tua. Hal ini juga disebabkan mereka masih memiliki semangat yang besar dalam berusaha. Menurut Rusli $d k k$ (1988), "golongan umur produktif adalah penduduk yang berusia antara 15 - 64 tahun."

Tingkat pendidikan merupakan faktor yang menunjang keberhasilan usaha pengusaha. Pendidikan yang lebih tinggi akan memudahkan bagi pengusaha untuk melihat peluangpeluang pasar, mencari informasi pasar dan mengembangkan usahanya sesuai permintaan pasar. Dengan pendidikan yang baik, seorang pengusaha akan memiliki kemampuan untuk menghadapi berbagai kendala yang mungkin timbul dan mencari solusi terbaik dalam 
menyelesaikannya. Sebaliknya dengan tingkat pendidikan yang rendah akan menyulitkan pengusaha dalam melakukan sntisipasi terhadap kendala yang mungkin dihadapinya dalam menjalankan usaha dagangnya.

Pengalaman berusaha juga merupakan salah satu faktor yang berpengaruh terhadap kelancaran aktivitas pengusaha pengolahan minyak jahe. Pengusaha yang memiliki pengalaman lebih lama akan lebih mudah menghadapi kesulitan dalam usahanya, dan umurnya memiliki jaringan usaha yang sudah cukup baik. Pengusaha yang memiliki pengalaman lebih lama mempunyai kemampuan untuk mengambil keputusan yang tepat sesuai keadaan yang diperlukan. Di samping itu dengan pengalaman yang telah dimilikinya, ia dapat bekerja secara lebih efisien dan terencana secara matang.

Jumlah tanggungan erat kaitannya dengan besarnya jumlah biaya hidup yang harus dikeluarkan. Semakin besar jumlah tanggungan dalam keluarga akan semakin besar biaya yang harus dikeluarkan, dan aka memperkecil jumlah modal yang dapat digunakan untuk menjalankan usaha. Untuk itu harus diimbangi dengan pencurahan tenaga kerja dalam keluarga, sehingga dapat menghemat jumlah biaya/upah yang harus dibayar kepada pihak lain.

\section{Teknik Pengolahan Minyak Jahe}

\section{- Persiapan bahan Baku}

Sebelum dilakukan proses pengolahan minyak jahe, perlu dilakukan beberapa persiapan yaitu rimpang jahe dicuci sampai bersih, kemudian direjang dengan mesin perejang dengan ketebalan $3 \mathrm{ml}$.

\section{- Penyulingan dengan sistem rebus (water distillation)}

Cara penyulingan dengan sistem ini adalah dengan memasukkan bahan baku ke dalam ketel penyuling yang telah berisi air kemudian dipanaskan. Uap yang keluar dari ketel dialirkan dengan pipa yang dihubungkan dengan kondensor. Uap yang merupakan campuran uap air dan minyak akan terkondensasi menjadi cair dan ditampung dalam wadah. Selanjutnya cairan minyak dan air tersebut dipisahkan dengan separator pemisah minyak untuk diambil minyaknya saja.

- Penyulingan dengan air dan uap (water and steam distillation)

Penyulingan dengan air dan uap ini biasa dikenal dengan sistem kukus. Cara ini sebenarnya mirip dengan sistem rebus, hanya saja bahan baku dan air tidak bersinggungan langsung karena dibatasi dengan saringan di atas air. Cara ini adalah yang paling banyak dilakukan pada dunia industry karena cukup membutuhkan sedikit air sehingga bisa menyingkat waktu proses produksi. Metode kukus ini biasa dilengkapi dengan kondensat yang keluar dari separator masuk kembali secara otomatis ke dalam ketel agar meminimkan kehilangan air.

- Penyulingan dengan uap langsung (direct steam distillation)

Pada sistem ini bahan baku tidak kontak langsung dengan air maupun api namun hanya uap bertekanan tinggi yang difungsikan untuk menyuling minyak. Prinsip kerja metode ini adalah membuat uap bertekanan tinggi didalam boiler, kemudian uap tersebut dialirkan melalui pipa dan masuk ketel yang berisi bahan baku. Uap yang keluar dari ketel dihubungkan dengan kondensor. Cairan kondensat yang berisi campuran minyak dan air dipisahkan dengan separator yang sesuai berat jenis minyak.

- Proses pengemasan dan Penyimpanan

Minyak atsiri jahe yang diperoleh selanjutnya disimpan atau dikemas di dalam botol kaca yang bewarna gelap dan kering. Kemudian dibungkus dengan aluminium foil dan disimpan di dalam ruangan ber AC atau sejuk. Setelah melalui proses pengemasan, minyak atsiri jahe siap dipasarkan kepada konsumen ataupun industri - industri yang bersangkutan. 


\section{Arus Kas Usaha Pengolahan Minyak Jahe PT. Raz Intan}

\section{Arus Pengeluaran}

Arus pengeluaran merupakan semua biaya yang dikeluarkan pengusaha untuk pembangunan dan operasional dalam usaha pengolahan minyak jahe.

\subsection{Biaya Investasi}

Biaya investasi merupakan seluruh biaya yang dikeluarkan dari mulai usaha tersebut dilaksanakan sampai usaha tersebut mulai berjalan atau dengan kata lain biaya investasi adalah biaya yang dikeluarkan untuk membeli barang-barang modal dan jasa yang diperlukan untuk membangun suatu usaha mulai dari pendirian tempat usaha pengolahan minyak jahe sampai menghasilkan produk. Adapun perincian biaya investasi pada usaha pengolahan minyak jahe di PT. Raz Intan Kabupaten Aceh Besar dapat dilihat pada tabel 3.

Tabel 3. Biaya Investasi Usaha Pengolahan Minyak Jahe di PT. Raz Intan Kabupaten Aceh Besar Tahun 2016

\begin{tabular}{|c|l|r|}
\hline No & \multicolumn{1}{|c|}{ Uraian } & \multicolumn{2}{|c|}{ Jumlah Biaya (Rp) } \\
\hline 1 & Perizinan Usaha & 30.000 .000 \\
\hline 2 & Bangunan & 75.000 .000 \\
\hline 3 & Mesin dan Peralatan & 166.750 .000 \\
\hline \multicolumn{2}{|c|}{ Jumlah } & 271.750 .000 \\
\hline
\end{tabular}

Sumber : Data Primer (diolah), 2016

Berdasarkan pada Tabel 3, jumlah biaya investasi yang dikeluarkan usaha pengolahan minyak jahe pada PT. Raz Intan di Kabupaten Aceh Besar sebesar Rp 271.750.000, yaitu untuk biaya pengurusan izin usaha sebesar Rp 30.000.000, untuk biaya bangunan usaha digunakan sewa tanah, bangunan pabrik, bangunan kantor yaitu Rp 75.000.000. Dan untuk biaya pembelian mesin serta biaya pembelian peralatan Rp 166.750.000 untuk penunjang dalam pengolahan minyak jahe.

\subsection{Biaya Operasional}

Biaya operasional adalah seluruh biaya yang dikeluarkan selama proses produksi berlangsung. Adapun perincian biaya operasional uasaha pengolahan minyak jahe pada PT. Raz Intan di Kabupaten Aceh Besar dapat dilihat pada Tabel 4.

Tabel 4. Biaya Operasional Usaha Pengolahan Minyak Jahe pada PT. Raz Intan di Kabupaten Aceh Besar Tahun 2016

\begin{tabular}{|c|c|c|}
\hline No & Tahun & Jumlah Biaya Operasional (Rp) \\
\hline 1 & 1 & 506.110 .000 \\
\hline 2 & 2 & 630.710 .000 \\
\hline 3 & 3 & 755.660 .000 \\
\hline 4 & 4 & 874.810 .000 \\
\hline 5 & 5 & 959.660 .000 \\
\hline 6 & 6 & 911.460 .000 \\
\hline 7 & 7 & 802.960 .000 \\
\hline 8 & 8 & 700.110 .000 \\
\hline 9 & 9 & 647.460 .000 \\
\hline 10 & 10 & 544.960 .000 \\
\hline
\end{tabular}

Sumber : Data Primer (diolah), 2016

Berdasarkan Tabel 4 diatas, rincian biaya operasional yang dikeluarkan berupa biaya dari pembelian bahan produksi, biaya iuran listrik dan biaya tenaga kerja. 


\section{Arus Penerimaan}

Arus penerimaan merupakan selisih dari nilai produksi yang dijual dan biaya yang dikeluarkan dalam penjualan suatu produk pada periode tertentu.

\section{Produksi Minyak Jahe, Harga jual dan Nilai Produksi}

Produksi merupakan suatu kegiatan yang dikerjakan untuk menambah nilai guna suatu barang atau menciptakan barang baru. Sedangkan nilai produksi merupakan pendapatan kotor yang berasal dari perkalian produksi dengan harga jual yang berlaku pada saat penelitian. Adapun perincian jumlah produksi, harga jual, dan nilai produksi usaha pengolahan minyak jahe pada PT. Raz Intan di Kabupaten Aceh Besar dapat dilihat pada Tabel 5.

Tabel 5. Jumlah Produksi, Harga Jual dan Nilai Produksi Pada Usaha Pengolahan Minyak Jahe PT. Raz Intan di Kabupaten Aceh Besar

\begin{tabular}{|c|c|c|c|r|}
\hline $\begin{array}{c}\text { Tahun } \\
\text { Ke }\end{array}$ & $\begin{array}{c}\text { Volume } \\
(\text { Kg/Tahun })\end{array}$ & Unit & Harga Jual (Rp) & Penjualan per Tahun (Rp) \\
\hline 1 & 325 & $\mathrm{Kg}$ & $1,800,000 / \mathrm{kg}$ & $585,000,000$ \\
\hline 2 & 417 & $\mathrm{Kg}$ & $1,800,000 / \mathrm{kg}$ & $750,600,000$ \\
\hline 3 & 510 & $\mathrm{Kg}$ & $1,800,000 / \mathrm{kg}$ & $1,083,600,000$ \\
\hline 4 & 602 & $\mathrm{Kg}$ & $1,800,000 / \mathrm{kg}$ & $1,200,600,000$ \\
\hline 5 & 667 & $\mathrm{Kg}$ & $1,800,000 / \mathrm{kg}$ & $1,134,000,000$ \\
\hline 6 & 630 & $\mathrm{Kg}$ & $1,800,000 / \mathrm{kg}$ & $884,600,000$ \\
\hline 7 & 547 & $\mathrm{Kg}$ & $1,800,000 / \mathrm{kg}$ & $775,800,000$ \\
\hline 8 & 468 & $\mathrm{Kg}$ & $1,800,000 / \mathrm{kg}$ & $633,600,000$ \\
\hline 9 & 431 & $\mathrm{Kg}$ & $1,800,000 / \mathrm{kg}$ & \\
\hline 10 & 352 & $\mathrm{Kg}$ & $1,800,000 / \mathrm{kg}$ & \\
\hline
\end{tabular}

Sumber : Data Primer (diolah), 2016

Berdasarkan dari Tabel 5 menunjukkan besar jumlah produksi minyak jahe mengalami peningkatan dari tahun 1 sampai tahun ke 5, ini dikarenakan permintaan minyak jahe terus bertambah setiap tahun. Namun pada tahun ke 6 sampai tahun ke 10 permintaan minyak jahe mengalami penurunan.

\section{Pendapatan Bersih}

Pendapatan bersih merupakan penentu bagi pengusaha apakah akan melanjutkan usaha tersebut atau tidak. Besarnya pendapatan bersih yang diterima pengolahan minyak jahe dapat dilihat pada Tabel 6.

Berdasarkan dari Tabel 6, dapat dilihat pada tahun 0 usaha pengolahan minyak jahe PT. Raz Intan belum memperoleh keuntungan dikarenakan pada tahun tersebut usaha belum berproduksi yaitu sebesar Rp (271.750.000). Biaya yang dikeluarkan pada tahun ke 0 merupakan biaya investasi. Pada tahun ke 1 sampai 10 usaha tersebut sudah memperoleh keuntungan atau pendapatan. 
Tabel 6. Pendapatan Bersih Pada Usaha Pengolahan Minyak Atsiri PT. Raz Intan di Kabupaten Aceh Besar Tahun 2016

\begin{tabular}{|c|r|c|r|}
\hline Tahun ke & $\begin{array}{c}\text { Penerimaan } \\
\text { (Benefit) }\end{array}$ & $\begin{array}{c}\text { Pengeluaran } \\
\text { (Cost) }\end{array}$ & \multicolumn{2}{|c|}{$\begin{array}{c}\text { Pendapatan Bersih } \\
\text { (Net Benefit) }\end{array}$} \\
\hline 0 & 0 & $271,750,000$ & $-271,750,000$ \\
\hline 1 & 585.000 .000 & 506.110 .000 & 78.890 .000 \\
\hline 2 & 750.600 .000 & 630.710 .000 & 120.190 .000 \\
\hline 3 & 918.000 .000 & 752.810 .000 & 165.190 .000 \\
\hline 4 & 1.083 .600 .000 & 875.310 .000 & 208.290 .000 \\
\hline 5 & 1.200 .600 .000 & 959.660 .000 & 240.940 .000 \\
\hline 6 & 1.134 .000 .000 & 910.960 .000 & 182.790 .000 \\
\hline 7 & 984.600 .000 & 801.810 .000 & 145.615 .000 \\
\hline 8 & 842.400 .000 & 696.785 .000 & 127.015 .000 \\
\hline 9 & 775.800 .000 & 648.785 .000 & 88.140 .000 \\
\hline 10 & 633.600 .000 & 545.460 .000 & \\
\hline
\end{tabular}

Sumber : Data Primer (diolah), 2016

\section{Analisis Finansial Usaha Pengolahan Minyak Jahe}

Analisis finansial merupakan bahan pertimbangan dalam mengambil suatu keputusan pada suatu usaha apakah layak atau tidaknya dijalankan. Kelayakan usaha pengolahan minyak jahe pada PT. Raz Intan dapat dilihat dengan menggunakan penilaian kriteria investasi, yaitu NPV, Net B/C, IRR, dan BEP. Nilai dari kriteria penilaian investasi dapat dilihat pada Tabel 7 sebagai berikut.

Tabel 7. Nilai Kriteria Penilaian Investasi Usaha Pengolahan Minyak Jahe pada PT. Raz Intan Tahun 2016

\begin{tabular}{|c|l|l|}
\hline No & \multicolumn{1}{|c|}{ Kriteria Investasi } & \multicolumn{1}{c|}{ Nilai } \\
\hline 1 & Net Present Value (NPV) & Rp 446.242.245 \\
\hline 2 & Net Benefit Cost Ratio (Net B/C) & 2,64 \\
\hline 3 & Internal rate of Return (IRR) & $49,50 \%$ \\
\hline 4 & Break Event Point (BEP) & 5 tahun, 4 bulan, 8 hari \\
\hline
\end{tabular}

Sumber : Data Primer (diolah), 2016

Berdasarkan dari Tabel 7, maka hasil perhitungan dengan penilaian kriteria investasi diperoleh NPV sebesar Rp 446.242.245, Net B/C sebesar 2,64 yang artinya setiap penambahan biaya Rp 1, maka akan diperoleh keuntungan sebesar Rp 2,64. IRR > tingkat suku bunga yang berlaku yaitu sebesar $49,50 \%$, dan BEP yang diperoleh yaitu 5,358, maka titik balik modal pada usaha pengolahan minyak jahe PT. Raz Intan dapat dikembalikan pada tahun ke 5 bulan ke 4, hari ke 8. Maka usaha pengolahan minyak jahe pada PT. Raz Intan ini masih layak untuk diusahakan karena NPV > 0, Net B/C > 1, IRR > tingkat suku bunga yang berlaku, dan BEP terjadi dalam umur ekonomis usaha.

\section{Analisis Sensitivitas Usaha Pengolahan Minyak Jahe}

Analisis sensitivitas (kepekaan) bertujuan untuk melihat kemungkinan-kemungkinan yang terjadi pada hasil analisis suatu usaha jika ada terdapat suatu kesalahan atau perubahanperubahan yang tidak dapat diduga sebelumnya dalam dasar-dasar perhitungan biaya dan manfaat. 
Adapun asumsi yang dianalisis dalam penelitian ini mempunyai dua kemungkinan yaitu cost naik $10 \%$ dan benefit turun $10 \%$.

- Kemungkinan I apabila biaya produksi (cost) naik 10\% sedangkan penerimaan (benefit) tetap, diperoleh hasil pada Tabel 8.

Tabel 8. Biaya Produksi (Cost) Naik 10\% sedangkan Penerimaan (Benefit) Tetap Usaha Pengolahan Minyak Jahe pada PT. Raz Intan Tahun 2016

\begin{tabular}{|c|l|l|}
\hline No & \multicolumn{1}{|c|}{ Kriteria Investasi } & \multicolumn{1}{|c|}{ Nilai } \\
\hline 1 & Net Present value (NPV) & $\mathrm{Rp} \mathrm{83.061.190}$ \\
\hline 2 & Net Benefit Cost Ratio (Net B/C) & 1,27 \\
\hline 3 & Internal Rate of Return (IRR) & $23,46 \%$ \\
\hline 4 & Break Event Point (BEP) & 6 tahun, 10 bulan, 4 hari \\
\hline
\end{tabular}

Sumber : Data Primer (diolah), 2016

Berdasarkan dari analisis sensitivitas dimana keadaan biaya produksi naik $10 \%$, sedangkan benefit tetap. Maka hasil perhitungan dengan penilaian kriteria investasi diperoleh NPV sebesar Rp 83.061.190, Net B/C sebesar 1,27 yang artinya setiap penambahan biaya Rp 1, maka akan diperoleh keuntungan sebesar Rp 1,27. IRR > tingkat suku bunga yang berlaku yaitu sebesar 23,46\%, dan BEP yang diperoleh yaitu 6,845, maka titik balik modal pada usaha pengolahan minyak jahe PT. Raz Intan dapat dikembalikan pada tahun ke 6 bulan ke 10, hari ke 4. Maka usaha pengolahan minyak jahe pada PT. Raz Intan ini masih layak untuk diusahakan karena NPV > 0 , Net B/C > 1, IRR > tingkat suku bunga yang berlaku, dan BEP terjadi dalam umur ekonomis usaha.

- Kemungkinan II apabila biaya produksi (cost) tetap sedangkan penerimaan (benefit) turun 10\%, diperoleh hasil pada Tabel 9.

Tabel 9. Biaya Produksi (Cost) Tetap sedangkan Penerimaan (Benefit) Turun $10 \%$ Usaha Pengolahan Minyak Jahe pada PT. Raz Intan

\begin{tabular}{|c|l|r|}
\hline No & \multicolumn{1}{|c|}{ Kriteria Investasi } & \multicolumn{1}{|c|}{ Nilai } \\
\hline 1 & Net Present Value (NPV) & Rp 38.436.965 \\
\hline 2 & Net Benefit Cost Ratio (Net B/C) & 1,14 \\
\hline 3 & Internal Rate of Return (IRR) & $20,38 \%$ \\
\hline 4 & Break Event Point (BEP) & 6 Tahun, 10 Bulan, 16 Hari \\
\hline
\end{tabular}

Sumber : Data Primer (diolah), 2016

Berdasarkan dari analisis sensitivitas dimana keadaan biaya produksi tetap, sedangkan benefit turun $10 \%$. Maka hasil perhitungan dengan penilaian kriteria investasi diperoleh NPV sebesar Rp 38.436.965, Net B/C sebesar 1,14 yang artinya setiap penambahan biaya Rp 1 maka akan diperoleh keuntungan sebesar Rp 1,14. IRR > tingkat suku bunga yang berlaku yaitu sebesar 20,38\% dan BEP yang diperoleh yaitu 6,879, maka titik balik modal pada usaha pengolahan minyak jahe PT. Raz Intan dapat dikembalikan pada Tahun ke 6, bulan ke 10, hari ke 16. Maka usaha pengolahan minyak jahe pada PT. Raz Intan ini masih layak untuk diusahakan karena NPV > 0 , Net B/C >1, IRR > tingkat suku bunga yang berlaku, dan BEP terjadi dalam umur ekonomis usaha.

\section{KESIMPULAN DAN SARAN}

Dari analisis finansial dengan menggunakan kriteria investasi diperoleh nilai NPV sebesar Rp 446.242.245, Net B/C yaitu 2,64, IRR sebesar 49,50\% dan BEP diperoleh pada tahun ke 5, bulan ke 4, hari ke 8. Dari analisis sensitivitas dengan hasil perhitungan kriteria 
biaya produksi (cost) naik 10\% dan penerimaan (benefit) tetap diperoleh NPV sebesar Rp 83.061.190, Net B/C yaitu 1,27, IRR sebesar 23,46\% dan BEP diperoleh pada tahun ke 6, bulan ke 10, hari ke 4. Untuk biaya produksi (cost) tetap dan penerimaan (benefit) turun $10 \%$ diperoleh NPV sebesar Rp 38.436.965, Net B/C 1,14, IRR sebesar 20,38\% dan BEP diperoleh pada tahun ke 6, bulan ke 10, hari ke 16. Hal ini menunjukkan bahwa usaha pengolahan minyak jahe pada PT. Raz Intan layak untuk diusahakan karena NPV > 0, Net B/C > 1, IRR > tingkat suku bunga yang berlaku, dan BEP terjadi dalam umur ekonomis usaha.

Diharapkan kepada para pengusaha minyak jahe agar dapat menjaga besarnya jumlah produksi dengan mengutamakan kualitas dan harga jual produk yang dianggap tidak berubahubah pada berbagai tingkat kegiatan, sehingga produk minyak jahe ini dapat diterima dengan seutuhnya oleh konsumen guna meningkatkan pendapatan pengusaha. Dan juga perlu adanya bantuan dari pemerintah yaitu kemudahan dalam proses perolehan modal usaha, dan melakukan pembinaan secara berkala kepada pelaku usaha, mengingat usaha pengolahan minyak jahe ini sangat potensial untuk dikembangkan.

\section{DAFTAR PUSTAKA}

BPS. 2002. Statistik Perdagangan Luar Negeri Indonesia, Ekspor. Jilid I. Jakarta.

Choliq A, Wirasasmittha R dan sofwan O, 1994, Evaluasi Proyek (Suatu pengantar), Pionir jaya. Bandung.

Guba, E.G dan Lincoln, Y.S. (1985). Naturalistic Inquiry. Beverly Hills: Sage Publication.

Ibrahim, Yacob. 2009. Studi Kelayakan Bisnis, Edisi Revisi. Rineka Cipta, Jakarta.

Kadariah, 1978. Pengantar Evaluasi Proyek. Fakultas Ekonomi Universitas Indonesia, Jakarta.

Rukmana, R. 2000. Usaha Tani Jahe. Kanisius. Yogyakarta

Rusli, S. dan Abdullah A. 1988. Prospek Pengembangan Kayu Manis di Indonesia. Bandung: Jurnal Litbang Pertanian 